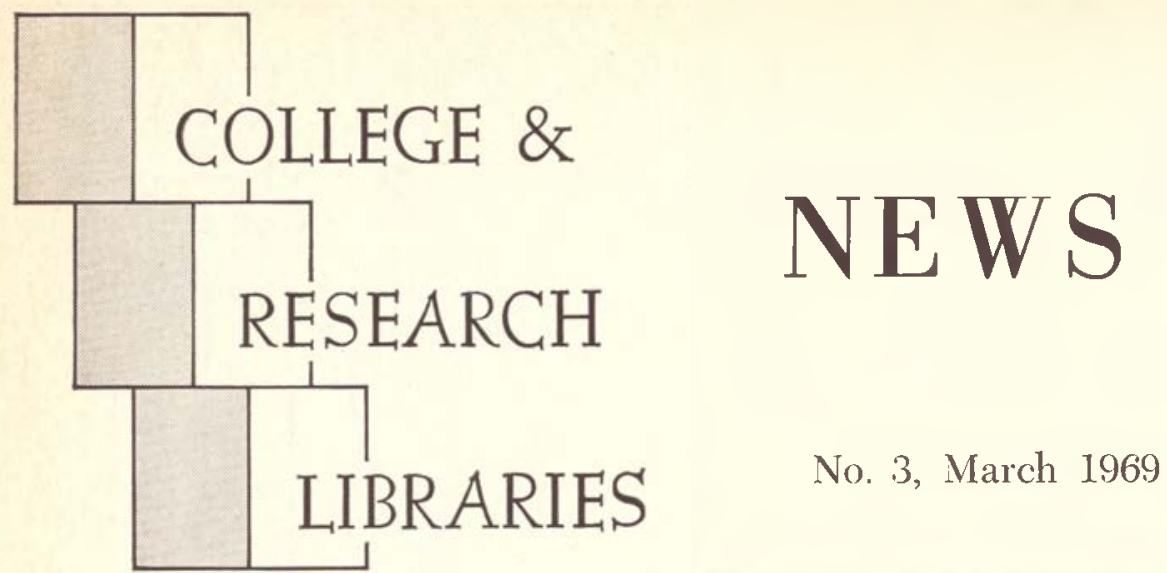

ACRL News Issue (A) of College \& Research Libraries, Vol. 30, No. 2

\title{
Librarians and Faculty Status
}

In September 1968 College and Research Libraries published an article on "Status of Librarians in Four Year State Colleges and Universities." The study was based on a questionnaire sent to 321 four-year state colleges and Iniversity centers across the United States. The compilation of statistics was based on a 57 per cent return. Status for librarians was equated with that of the academic faculties in regard to rank and titles, promotion criteria, tenure, sabbatical leave. rates of pay, holidays and vacations, participation in faculty government, and fringe benefits. The article showed that only 26 of 183 reporting libraries granted full faculty status to their librarians. Since the publication of the article the authors have received many inquiries as to the actual names of the institutions which enjoy full faculty status. The following 24 of 26 institutions were kind enough to authorize us to disclose their names:

1. Colorado State University; Fort Collins, Colo.

2. Eastern Illinois University; Charleston, Ill.

3. Illinois State University; Normal, Ill.

4. Fort Hays Kansas State College; Hays 2, Kan.

5. Northwestern State College of Louisiana; Natchitoches, La.

6. Moorhead State College; Moorhead, Minn.

7. Winona State College; Winona, Minn.

8. Southeast Missouri State College; Cape Girardeau, Mo.

9. Southwest Missouri State College; Springfield, Mo.

10. Glassboro State College; Glassboro, N.J.

11. Newark State College; Union City, N.J.

12. Appalachian State University; Boone, N.C.
13. Northwestern State College; Alva, Okla.

14. Millersville State College; Millersville, Pa.

15. Shippensburg State College; Shippensburg, $\mathrm{Pa}$.

16. Westchester State College; IVestchester, $\mathrm{Pa}$.

17. Sam Houston State College; Huntsville, Texas

18. University of Houston; Houston, Texas

19. Western Washington State College; Bellingham, Wash.

20. Wisconsin State University; Eau Claire, Wisc.

21. Wisconsin State University; LaCrosse, Wisc. 22. Stout State University; Menomonie, Wisc.

23. Wisconsin State University; Oshkosh, Wisc.

24. Wisconsin State University; Stevens Point, Wisc.

\section{SUNY LIBRARIANS ASSOCIATION BEING FORMED}

Elected representatives from the various library units of the State University of New York have drafted a constitution and bylaws for a statewide association of SUNY librarians.

The association aims to advance the professional status of the librarians in SUNY and to further develop the principles and standards of academic librarianship.

The libraries of SUNY range in size and complexity from those of two year community colleges through university centers and medical schools. 


\section{Our books}

are like

everyone

else's-but

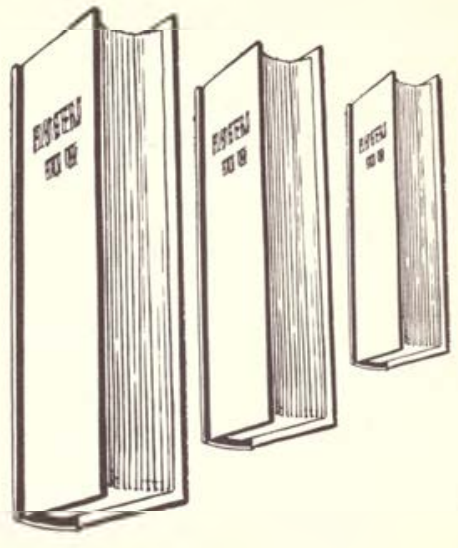

our Service is unique.

Yes, we specialize in service. For at Taylor-Carlisle, service is not just an expression. It is the mainstay of our policy, it is the actual reason for our existence, it is the one outstanding element that has meant so much to our clientele and contributed to our own continued growth. We supply books-but what we sell is service.

Send for our brochure and terms.
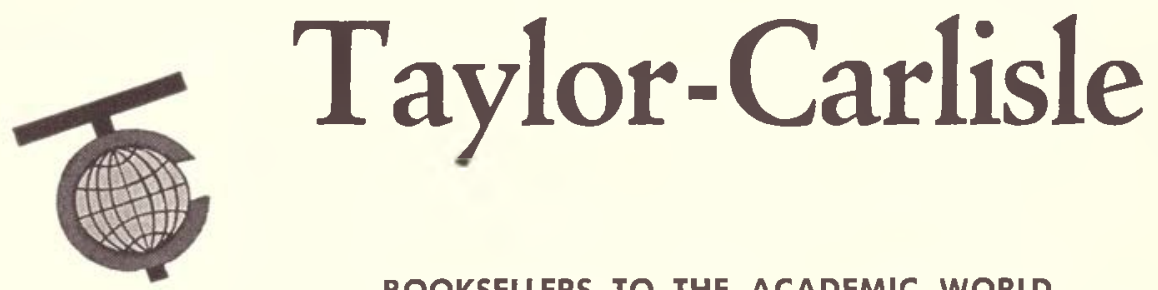

\section{BOOKSELLERS TO THE ACADEMIC WORLD}

NEW YORK: 115 East 23rd Street, New York, N.Y. 10010

FLORIDA: Winter Park Mall, Winter Park, Florida 32789

TEXAS: 1 Shell Plaza, Houston (Opening soon)

"Service" is the reason so many librarians order with confidence from Taylor-Carlisle. 


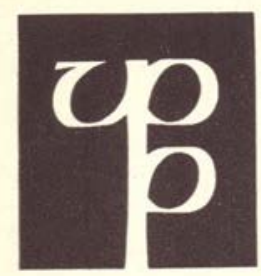

\section{UNIVERSITY of \\ PENNSYLVANIA \\ PRESS}

Printing and Publishing in the United States

New

\section{BOOK PIRATING IN TAIWAN}

\section{David Kaser}

The first study of unauthorized reprints of copyrighted books emanating from Taiwan.

$\$ 6.50$

JOSEPH CHARLESS: Printer in the Western Country

\section{David Kaser}

"Kaser relates the professional activities of Charless in considerable detail and since Charless was a pioneer as well as editor, bookseller, publisher, apothecary, hosteler, and entrepreneur attention is also given to the times and the character of the man." $\$ 4.50$

Journal of American History

MESSRS. CAREY AND LEA OF PHILADELPHIA: A Study in the History of the Booktrade

David Kaser

"Specialists in American literary and business history will naturally find it valuable, but its audience can be anyone interested in the roots of American culture . . . readable and quietly fascinating."

$\$ 4.00$

-Pennsylvania History

\section{THE COST BOOK OF CAREY \& LEA, |825-|838}

\section{David Kaser}

"This book will be of much value to bibliographers, economics historians, and literary scholars. It will hold great fascination for others who have any curiosity about early printing and publishing in this country."

$\$ 10.00$

-Journal of American History

\section{UNIVERSITY of PENNSYLVANIA PRESS}

\section{Philadelphia 19104}




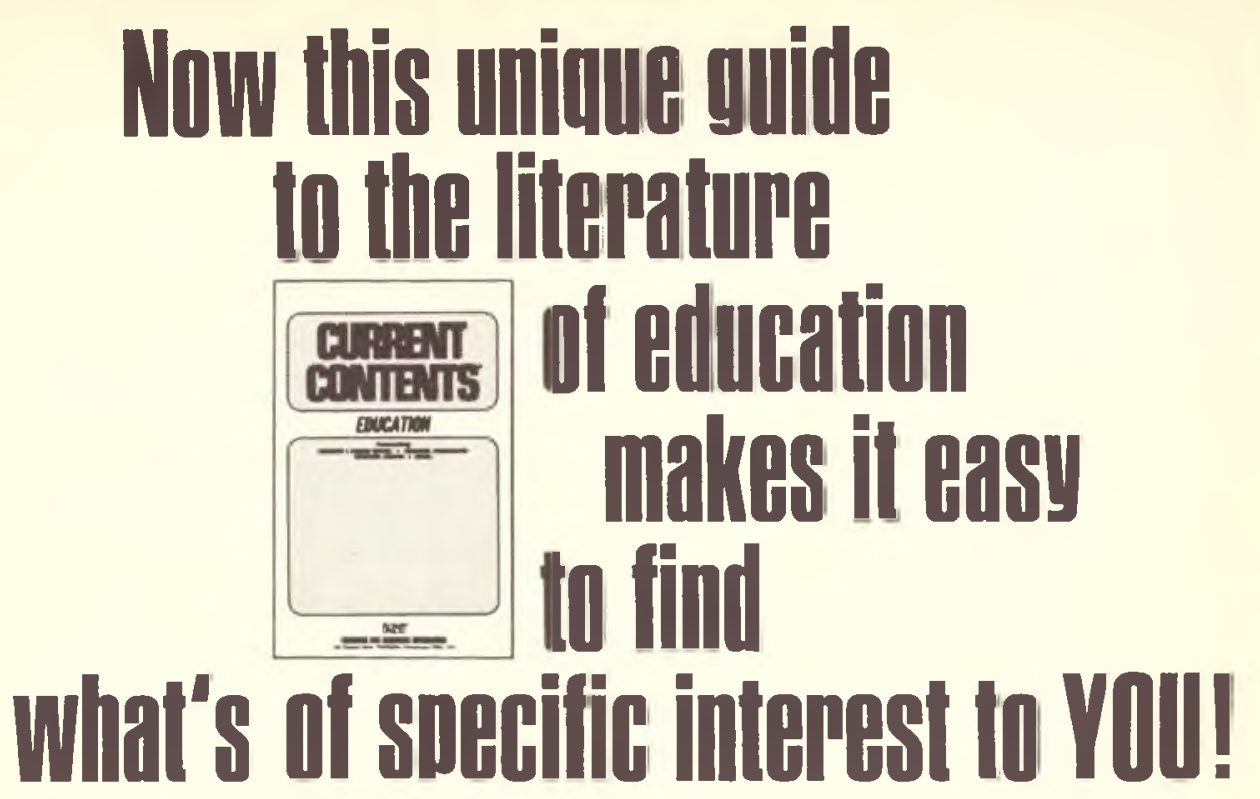

Every week CURRENT CONTENTS ${ }^{\circledR} /$ Education brings you a pocket-size guide to articles and reports in journals important to you as an educator. Here's how you benefit:

No longer do you spend time searching through stacks of periodicals hoping to spot something of specific interest to you. CURRENT CONTENTS ends that drudgery!

A quick thumbing through your weekly CURRENT CONTENTS solves your reading-selection problem-you find reproduced the Table of Contents of the literature that helps you keep abreast of developments in education. In ancillary fields, too. 689 United States and foreign publications will be covered. Write-or better, phone-for complete information on how CURRENT CONTENTS/Education can serve as your personal research librarian. We'll include data on the advantages of using our Original Article Tear Sheet service (OATS) ${ }^{\circledR}$ in connection with CURRENT CONTENTS.

In Philadelphia: contact ISI, 325 Chestnut St., Philadelphia, Pa. 19106, Telephone (215) 923-3300. In

Washington D.C.: contact ISI, 7315 Wisconsin Ave., Suite 500, Bethesda, Md. 20014, Telephone

(301) 657-2366. In Europe: contact Mr. Anthony Cawkell, 132 High Street, Uxbridge.

Middlesex. England Telephone Uxbridge 30085 or Mr. Peter Aborn, 6 Square Moncey, Paris 9, France. Telephone TRI 6738. In Japan: contact Mr.

Takashi Yamakawa, Tsutsumi Building, 13-12 1-chome, Shimbashi Minato-Ku, Tokyo, Japan. Telephone (591) 5181-6.

Institute for Scientific Information
325 Chestnut Street, Philadelphia, Pennsylvania 19106, U SA 